\title{
Talent Management Predictors that Adversely Affect Job Satisfaction at a South African Parastatal
}

\author{
Patrick Lekgothoane, Molefe Maleka, Zeleke Worku \\ Dept. People Management and Development, Tshwane University of Technology, South Africa \\ LekgothoaneP@tut.ac.za, Malekam@tut.ac.za,WorkuZ@tut.ac.za
}

\begin{abstract}
The purpose of the study was to quantify talent management predictors that adversely affect job satisfaction (JS). The literature review revealed that talent management predictors (i.e. neglecting experience during recruitment and appointment of managers, and supervisors' lack of confidence in the achievement of goals) adversely affected JS. The research design was cross-sectional, pre-experimental, and a survey. Data were collected at a parastatal business unit with a population size of 800.Using calculating statistics, the appropriate sample size was $n=204$. The sample was stratified by gender and occupation. Data were collected by means of a validated questionnaire and analyzed by means of frequencies, and logit analysis. Bayesian analyses were used to test the hypotheses. The three hypotheses were supported; showing that employees are more likely to be dissatisfied if their experience was not considered during recruitment, if their experience was neglected when managers were appointed irrespective of their gender, and if supervisors lacked confidence that the organizational strategic goals would be achieved. Recommendations for future research are made. This study has implications for managers in the sense that if they do not factor in experience, i.e. during recruitment and appointment, they might have supervisors who do not have confidence in expressing the strategic goals of the parastatal. This study adds value to the existing body of knowledge by quantifying talent management factors using odds ratios to determine talent management predictors that adversely affect JS.
\end{abstract}

Keywords: Appointment, confidence, experience, recruitment, parastatal

\section{Introduction}

The study was driven by the need to identify and quantify existing and unexplored possible predictors of JS to enhance the overall productivity of parastatals (or state-owned companies). Productive parastatals in China that operate professionally contribute immensely to the gross domestic product (GDP) of the country (Scharmer \& Kauder, 2013). A parastatal, or state-owned enterprise (SOE), is an entity partially owned by the state and private entities (Mutanda, 2014). The reason why JS is widely researched is that it has a positive relationship with life satisfaction, organizational commitment, and job performance, which all contribute to organizational success (Buitenbach \& De Witte, 2005). Research conducted at a parastatal in Kenya reported that increased JS is valuable to the organization since it contributes positively to employee performance and productivity (Otieno, 2016). It is important to draw attention to other instances or dimensions that may either increase or decrease JS in various organizations, especially parastatal organizations. For instance, the staff at a South African parastatal ranked job security and pay as predictors of JS (Carolissen \& Smith, 2014). A different and worrying concern in the latter regard is organizations that are no longer financially viable. A case in point is a parastatal in Zimbabwe where employees who were not paid for lengthy periods were tempted to engage in corrupt activities to augment their delayed salaries (Maunganidze, Mashavira \& Mapira, 2017).

The purpose of this study is to assess the strength of the association between the proposed factors of recruitment and selection, gender, organizational culture, interactive justice, transformational leadership and organizational citizenship behavior, and JS. It is also important to guard against employees' unhappiness, which can result in their intention to quit, by deriving means to entice them to stay. The latter is substantiated by Gopane and Magang (2016), who found that employee turnover at a parastatal in Botswana, as a result of dissatisfied employees, was rampant due to a lack of retention strategies, which included pay, challenging and meaningful work, and training opportunities. Similarly, a study conducted by Amakiri and Luke (2015) at a parastatal in Nigeria revealed that a lack of effective job design, job enlargement, and job rotation hindered an employee's potential to acquire new skills and to grow, and lowered their commitment and JS, as also indicated by Saari and Judge (2004). Job dissatisfaction can also emanate from the absence of promotional opportunities and good leadership (Ongunlana, Oshinaike \& Ibrahim, 2016; Munyengabe et al., 2017). Perceptions of stress differ among employees and these were conceptualized as antecedents of job 
dissatisfaction (Rossler, 2012; Bussing et al., 2017). Similarly, the perceptions of downsizing organizations proved to cause dissatisfaction in younger employees and also among those who survived downsizing in general (Lahner et al., 2014). From this literature, it can be deduced that JS is a complex construct that is predicted by many factors.

This study is important because at the time it was conducted, there were many talent management issues experienced at the parastatal. The annual report, which cannot be discussed at length in this paper due to the confidentially clause signed by the researchers, revealed that managers had to be trained. The organization was also taken to a dispute resolution institution, and was ruled against for unfair labor practices in terms of recruitment and selection practices and training. It is envisaged that through this study, the management of the parastatal will be empowered with information that will assist them to keep employees motivated and performing optimally. Other JS studies conducted in the parastatals managed to identify lack of trained managers, gender inequality treatment, and lack of commitment or organizational citizenship behavior as factors that affect JS, but these studies were qualitative in nature (Maleka, 2012; Maleka \& Rankhumise, 2014). A study conducted at Eskom, a parastatal, did not show a difference in employees of different categories and did not use statistics like logit analysis to determine predictors of JS (Khoza \& Kanjere, 2014). The literature review indicated that was little research that quantified talent management predictors using robust statistical tests like logit and Bayesian analyses. The research question of the study is: What are talent management predictors that adversely affect the predictors of JS at a parastatal? In order to answer the research question, the following objectives were developed:

- to determine how the respondents, rate the talent management predictors of JS; and

- to quantify how talent management predictors adversely affect JS.

\section{Literature Review}

Talent management predictors of JS: According to Labuschagne, Bosman and Buitendach (2005), JS is a complex variable that is influenced by talent management factors like recruitment and confidence in strategy implementation. The researchers focused on talent management factors that adversely affect JS (Buitenbach \& De Witte, 2005; Kianto, Vanhala \& Heilmann, 2016; Mensah \& Bawole, 2017). In this study, the focus was on neglecting experience during the recruitment and appointment of managers, and supervisors' lack of confidence in the achievement of goals.

Recruitment and JS: One of the talent management predictors of JS is recruitment, which refers to the attraction and invitation of qualified candidates to apply for vacant positions in an organization (Nel et al., 2016:445). New recruits often experience the hangover effect, which refers to declining job attitudes. It is important to consider various factors that influence the effective recruitment and selection of employees. For instance, the Public Service Commission (PSC, 2015) reported that seeking relevant experience for recruitment purposes provides clarity about the applicant's candidacy and assists in making appropriate selection decisions. Similarly, Jha and Bhattachryya (2012) asserted that competency and experience are vital tools for human resource planning. The recruitment and selection of candidates based on who they know are claimed to be rife in Nigeria, to the extent that it compromises organizational performance (Adisa et al., 2007). Using nepotism as a criterion for recruitment had a negative effect on JS (Bute, 2011; Maleka, 2012; Maleka \& Rankhumise, 2014). It was also alleged that candidates with no experience at South African public organizations were "parachuted" to senior positions because of their proximity to influential top managers (PSC, 2015). Based on the literature, the following hypothesis is made:

Hypothesis $(\mathrm{H}) 1$ : Employees are more likely to be dissatisfied if their experience was not considered when recruiting them.

Gender of management appointment and JS: Managers should avoid discrimination in dispatching opportunities to employees. This is evident in a study conducted by Jooste (2014), where 73\% of the respondents disagreed that they had equal opportunities for advancement in their organization based on gender. Women, in particular, experienced low JS due to being denied promotions to advance to top management positions (Kithinji, 2016). However, the post grading of men was found to be statistically insignificant to those of women, rendering the practical value of the difference small (Steyn, 2014). The following hypothesis can thus be made: 
(H)2: Employees are more likely to be dissatisfied that their experience did not assist them to be appointed to a management position because of their gender.

Confidence in the achievement of strategic goals and JS: Supervisors who do not have experience and do not know how to implement organizational objectives cause employee dissatisfaction (Ben-Hur \&Kinley, 2016). The PwC (2015) Technical Report recommended that supervisors should adopt ownership and management principles by being flexible in making decisions, setting the tone, and acting as a standard bearer and a setter of boundaries and/or goals. In addition, the report recommended that leaders should establish a climate of positive teamwork, be receptive to daily activities, avoid micromanaging, and clarify goals to encourage a sense of achievement, as well as through continuous professional development (Dacri, 2015; Tufail et al., 2016). The following hypothesis can thus be made:

(H)3: Employees are more likely to be dissatisfied if their supervisors expressed a lack of confidence that strategic organizational goals will be achieved.

\section{Methodology}

This section discusses the research design, measures, data collection and analysis, and procedure.

Research design: The design of study was cross-sectional and descriptive. In order to address the research question, a survey and pre-experimental design were deemed appropriate (Bless, Higson-Smith \& Sithole, 2013). The target population was all employees of the state owned enterprise. The sample was stratified by gender and population group. The total number of employees (population size) was equal to 800 . A sample of size 204 was determined for the study by using the following equation:

$n=\frac{Z^{2}{ }_{1-\frac{\alpha}{2}} \times P(1-P)}{d^{2}}$

In the expression shown above, $\mathrm{n}$ denotes the adjusted sample size of study. The letter $\mathrm{Z}$ denotes the standard normal random variable. The symbol alpha denotes the level of significance (5\%). The letter P den otes the percentage of employees who are not satisfied with their jobs (50\%), and d denotes the margin of error (0.048). The sample distribution of the respondents' gender and occupation is displayed in Table 1 . As can be observed, the majority (61.27\%) of the respondents were male. The age category with the largest amount of respondents was 18 to 35 years (62.25\%). Most (87.25\%) of the respondents were not in management positions.

Table 1: Sample distribution

\begin{tabular}{ll}
\hline Biographical variables & Frequency \\
\hline Gender & Male: $125(61.27 \%)$ \\
Age category in years & Female: $79(38.73 \%)$ \\
& 18 to 35 years: $127(62.25 \%)$ \\
& 36 to 50 years: $63(30.88 \%)$ \\
Occupational level & 51 years or more: $14(6.86 \%)$ \\
& Non-management: $178(87.25 \%)$ \\
& Management: $21(10.29 \%)$ \\
Duration of service in years & Senior management: $5(2.45 \%)$ \\
& Two or less: $19(9.31 \%)$ \\
& Three to four: $12(5.88 \%)$ \\
& Five or more: $173(84.80 \%)$ \\
\hline
\end{tabular}

\section{Source: Study data}

Measures: The questionnaire comprised two sections. Section A comprised biographical information. Section $B$ comprised scales that were measured on a four-point Likert scale, where $1=$ strongly agree, $2=$ agree, 3 = disagree, and $4=$ strongly disagree.

Recruitment and selection: Five items were adapted from Maleka's (2012) open-ended interview protocol, of which one of the items was "Failure to use relevant experience for recruitment". 
Gender: Five items were adapted from Maleka's (2012) open-ended interview protocol, of which one was "Managerial qualification assists employees to be appointed in management positions regardless of their gender".

Labor relations: Five items were adapted from Maleka's (2012) open-ended interview protocol, of which one was "There are many disciplinary hearings in the department".

Transformational leadership: Five items were taken from Maleka's (2012) open-ended interview protocol, of which one was "My immediate supervisor articulates a compelling vision of the future".

Interactive justice: Five items were taken from Farh, Earley and Lin's (1997) interactive justice scale, which had a Cronbach's alpha of 0.88. One of the items was "My supervisor provides justification for my performance appraisal score".

Job satisfaction: Five items were taken from Spector's (1985) scale, of which one was "The pay I receive is fair".

Data collection and analysis: Data were collected at one business unit of a parastatal in 2017, and the questionnaire was pretested on 10 respondents at the parastatal. From the pretesting, it was clear that the respondents understood the questionnaire items. In order to analyze the data, frequencies were used to describe the sample distribution (refer to Table 1). In this study, JS was a dependent variable. In order to make it a binary, where: $1=$ if employee has no JS, and $0=$ otherwise or employee has JS. The independent variables were recruitment and selection, gender, labor relations, transformational leadership, interactive justice, and JS. The data were coded in Microsoft Excel and exported into STATA version 14 for analysis. As suggested by Hair et al. (2010), logit analysis (Hosmer, Lemeshow \& Sturdivant, 2013) and Bayesian analysis (Browne \&Goldstein, 2010) were used to identify predictors or factors that adversely affect JS. These statistics (logit and Bayesian analyses) can be conducted when the sample size is around 200 (Legoabe, 2017). To achieve content validity, as suggested by Spector (2012), the researchers requested human resource management (HRM) experts to validate the questionnaire. The Hosmer-Lemeshow goodness-of-fit test was equal to 0.2670 , which was $>0.05$. The overall classification was $89.61 \%$, the sensitivity to the fitted logistic regression model was equal to $62.39 \%$, and the percentage specificity for the fitted logistic regression model was equal to $89.47 \%$. Based on the Hosmer-Lemeshow, overall classification, logistic, and specificity tests, the researchers concluded that the model was reliable. Differences tests that were conducted in this study were the T-test and Kruskal-Wallis test (Bless et al., 2013).

Procedure: Prior to data collection at the parastatal, the researchers were given ethical clearance by the university. Before data collection, the respondents were given an informed consent form to complete and they were not coerced or forced to complete the questionnaire. The respondents were also informed that they could stop participating in the study at any time. The respondents were informed of the importance of the study, that the results of the study were for academic purposes, and that the intention of the study was to identify factors that predict or adversely affect JS. The results of the study would be shared with management in order for them to improve the working conditions of the employees so that they would be satisfied and ultimately perform optimally.

\section{Results}

This section is divided into two subsections, namely descriptive statistics (frequencies) and inferential statistics.

Descriptive statistics: From Figure 1 it can be observed that $65.20 \%$ of the respondents were satisfied and $34.80 \%$ were not satisfied. This trend is in line with Korschun, Bhattacharya and Swain's (2014) study, which showed that $65.19 \%$ of the respondents were satisfied and $34.81 \%$ were dissatisfied. 
Figure 1: Overall JS of employees $(n=204)$

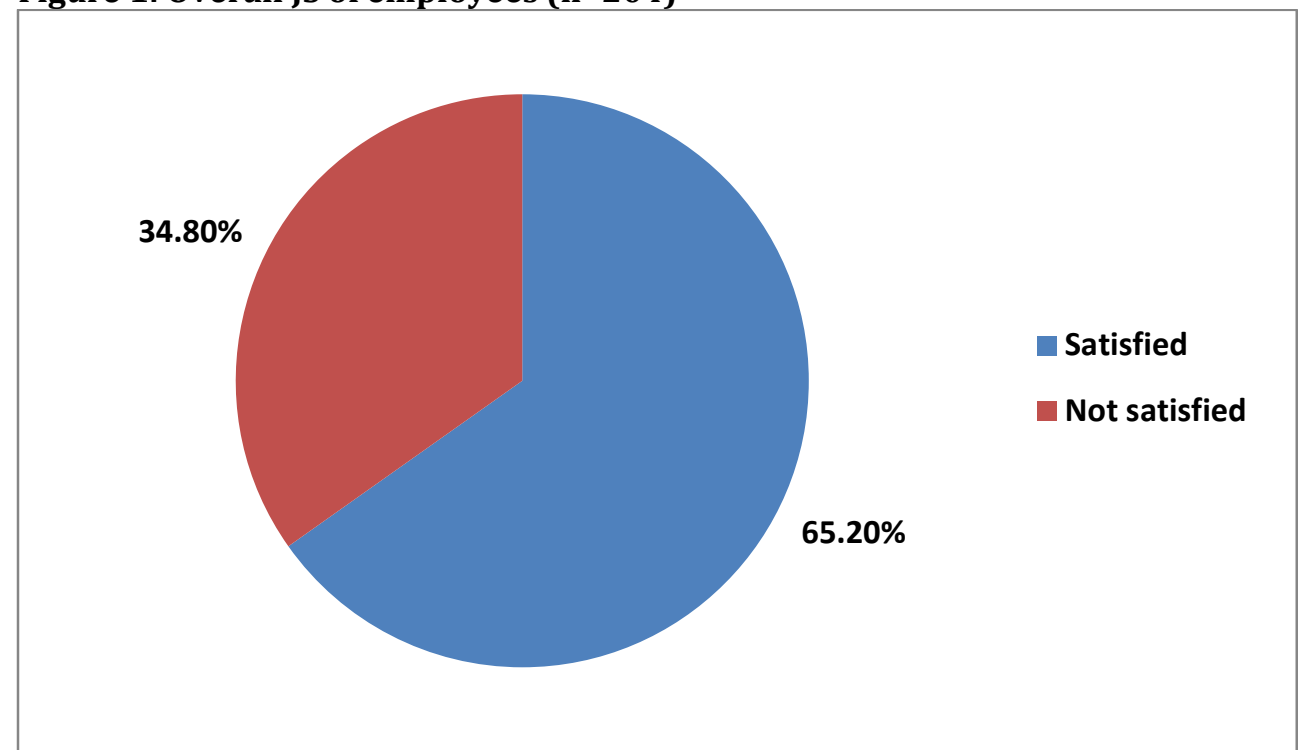

\section{Source: Study data}

After conducting logit and Bayesian analyses, three predictors were left in the model. The frequencies of those variables are shown in Table 2 . The majority of the respondents (59.80\%) disagreed, compared to $40.20 \%$ who agreed, that experience was considered when recruiting employees. The majority of the respondents (55.88\%) disagreed, compared to $44.12 \%$ who agreed, that experience was a catalyst to be appointed to management regardless of gender. The majority of the respondents (50.98\%) disagreed, compared to $49.02 \%$ who agreed, that supervisors were confident that organizational goals will be achieved.

Table 2: Frequencies of variables that adversely affect JS

\begin{tabular}{|c|c|}
\hline Variables & Frequency and percentages \\
\hline \multirow[t]{4}{*}{ Experience is considered when recruiting employees. } & Strongly agree: 39 (19.12\%) \\
\hline & Agree: $43(21.08 \%)$ \\
\hline & Disagree: 53 (25.98\%) \\
\hline & Strongly disagree: $69(33.82 \%)$ \\
\hline \multirow{4}{*}{$\begin{array}{l}\text { Experience assists employees to be appointed to } \\
\text { management positions regardless of their gender. }\end{array}$} & Strongly agree: 33 (16.17\%) \\
\hline & Agree: 57 (27.94\%) \\
\hline & Disagree: $65(31.86 \%)$ \\
\hline & Strongly disagree: $49(24.02 \%)$ \\
\hline \multirow{4}{*}{$\begin{array}{l}\text { My immediate supervisor expresses confidence that } \\
\text { goals will be achieved. }\end{array}$} & Strongly agree: 17 (8.33\%) \\
\hline & Agree: $83(40.69 \%)$ \\
\hline & Disagree: $72(35.29 \%)$ \\
\hline & Strongly disagree: $32(15.69 \%)$ \\
\hline
\end{tabular}

\section{Source: Study data}

Inferential statistics: Discussed in this section are the difference tests and logit and Bayesian analyses.

Differences test: Before selecting a difference test, the researchers calculated a normality test. The histograms were bell shaped and the Q-Q Plot, not shown in the study, did not deviate from the zero line, suggesting that the data were normally distributed (Pallant, 2016). The researchers therefore conducted a Ttest. An independent samples t-test was conducted to compare respondents' perceptions of how experience was considered when recruiting employees' scores for males and females. There were no significant differences in scores for males and females. An independent samples T-test was conducted to compare respondents 'perceptions of experience in appointing managers irrespective of gender for males and females. There was a statistical significant difference in scores for males $(M=2.53, S D=1.02)$ and females $(M=2.82$, 
$\mathrm{SD}=1.01 ; \mathrm{t}=-2.01, \mathrm{p}=0.05$, two-tailed). The magnitude of the differences in means (mean difference $=-0.29$, CI: -0.53 to -0.01 ) was very large (eta squared $=0.51$ ). An independent samples T-test was conducted to compare how the respondents perceived how that their immediate supervisor expressed confidence that goals will be achieved. There was no significant difference in the scores of males and females.

A Kruskal-Wallis test revealed that there was no statistical difference in how respondents perceived whether experience was considered when recruiting employees, whether experience assisted employees to be appointed to management positions regardless of their gender, and that their immediate supervisor expressed confidence that goals would be achieved in three groups (i.e. age categories in years). A KruskalWallis test revealed a statistical significant difference in how the respondents perceived whether experience was considered when recruiting employees across three groups (Group 1, $\mathrm{n}=178$, non-management: Group $2, \mathrm{n}=21$, management, Group 3, $\mathrm{n}=5$ senior management), $\chi^{2}(2)=10.47, \mathrm{p}=0.01$. Group 1 (nonmanagement) recorded the highest median $(M d=3)$, with the other two groups recording the median value of 2.A Kruskal-Wallis test revealed a statistically significant difference in how respondents perceived whether experience assisted employees to be appointed to management positions regardless of their gender across three groups (Group 1, $\mathrm{n}=178$, non-management: Group 2, $\mathrm{n}=21$, management, Group 3, $\mathrm{n}=5$ senior management, $\chi^{2}(2)=8.1, p=0.01$. Group 1 (non-management) recorded the highest median $(M d=3)$ than the other two groups which recorded the median values of 2 .There was no statistical significant difference in how respondents perceived whether their immediate supervisor expressed confidence that goals would be achieved in three groups (i.e. occupational levels).A Kruskal- Wallis test revealed a statistical significant difference in terms of respondents' perceptions on whether experience was considered when recruiting employees across three groups (Group 1, $\mathrm{n}=19,2$ years or less, Group 2, n=12, 3 to 4 years, Group 3, n=173, 5 or more years), $\chi^{2}(2)=8.45, p=0.02$. Group 3 (5 or more years) recorded the highest median score $(\mathrm{Md}=3)$, while the other two groups recorded the median value of 2.A Kruskal-Wallis test revealed that there was no statistical difference in how respondents perceived whether experience was considered when recruiting employees, whether experience assisted employees to be appointed to management positions regardless of their gender, and whether their immediate supervisor expressed confidence that goals would will be achieved in three groups (i.e. years of service).

Logit analysis: Odds ratios were used to quantify or measure the likelihood of the predictors that adversely affect JS (Graham, 2013; Sheldrick, Chung \&Jacobson, 2017). As can be observed in Table 3, respondents were 3.36 times more likely to be dissatisfied if their experience was not considered when recruiting employees; therefore, $\mathrm{H} 1$ is supported. The data revealed that respondents were 2.63 times more likely to be dissatisfied if their experience did not assist them to be appointed to management positions regardless of their gender. Based on the study results, $\mathrm{H} 2$ is supported. It was also found that respondents were 2.16 times more likely to be dissatisfied if their supervisors did not express confidence that organizational strategic goals will be achieved. Hence, H3 is supported.

Table 3: Predictors of lack of JS using logit analysis

\begin{tabular}{|c|c|c|}
\hline Factors that adversely affect JS at the workplace Odds ratio & P-value & $\begin{array}{ll}95 \% & \text { confidence } \\
\text { interval } & \\
\end{array}$ \\
\hline 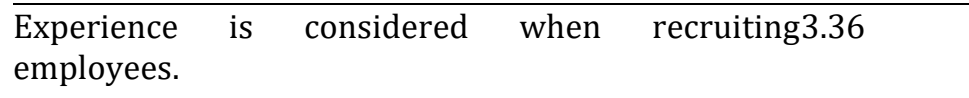 & 0.001 & $(2.19,5.68)$ \\
\hline $\begin{array}{l}\text { Experience assists employees to be appointed in } 2.63 \\
\text { management positions regardless of their gender. }\end{array}$ & 0.003 & $(1.85,4.93)$ \\
\hline $\begin{array}{l}\text { My immediate supervisor expresses confidence that } 2.16 \\
\text { goals will be achieved. }\end{array}$ & 0.004 & $(1.13,4.14)$ \\
\hline
\end{tabular}

\section{Source: Study data}


Bayesian analysis: In order to confirm the reliability of the logit analysis, the researchers conducted a Bayesian analysis, as suggested by Revuelta and Ximenez (2017). As can be observed from Table 4, three predictors that affected JS also emerged from the data. It must be noted that Bayesian analysis does not have odds ratios, but shows the regression coefficient. In order to convert the regression coefficient, the following equation was used:

$e^{\text {regression coefficient }}=\mathrm{OR}$.

For example, $e^{1.21}$ (i.e. "Experience is considered when recruiting employees") $=3.36$. The same statistical procedure could be conducted to convert the regression coefficients of the other two factors.

Table 4: Regression coefficients estimated from Bayesian analysis

\begin{tabular}{lllll}
\hline Factors that adversely affect JS at the workplace & $\begin{array}{l}\text { Regression } \\
\text { coefficient }\end{array}$ & P-value & $\begin{array}{l}\mathbf{9 5 \%} \\
\text { interval }\end{array}$ & confidence \\
\hline $\begin{array}{l}\text { Experience is considered when recruiting employees. } \\
\begin{array}{l}\text { Experience assists employees to be appointed to } \\
\text { management positions regardless of their gender. }\end{array}\end{array}$ & 0.97 & 0.000 & $(0.78,1.94)$ \\
$\begin{array}{l}\text { My immediate supervisor expresses confidence that } \\
\text { goals will be achieved. }\end{array}$ & 0.77 & 0.000 & $(0.42,1.56)$ \\
\hline
\end{tabular}

\section{Source: Study data}

\section{Discussion and Conclusion}

The purpose of the study was to quantify talent management predictors that adversely affect JS. The data revealed that respondents at the parastatal were dissatisfied that their experience was neglected during the recruitment and selection processes. This implied that the parastatal appointed inexperienced people and focused more on achieving targeted transformation, as reported in the parastatal's 2014 integrated report. The unintended consequence of neglecting experienced employees during the selection process is a decline in productivity or performance. This finding contradicts the PSC's (2015) findings, which asserted that the relevant experience of a candidate assists in making appropriate decisions, and HRM planning (Jha \& Bhattachryya, 2012; Witt, 2017). It was found that respondents in non-management positions, and those with five and more years agreed that experience was neglected during the recruitment and selection process. It was found that experience was also neglected when people were appointed to management positions, irrespective of gender. This also implied that appointments were made in management without considering experience. A study conducted in South Africa showed that this trend of a lack of a talented pool of managers will continue (Van Eeden, 2014). The PwC (2015) Technical Report showed that managers who were inexperienced were not able to make decisions, set the tone, and act as a standard bearer and a setter of boundaries and/or goals. A previous study at an SOE revealed that nepotism, or knowing people in top positions, was the criterion used to appoint managers (Maleka, 2012; Maleka \& Rankhumise, 2014). The mean score of females were slightly higher than males in terms of how they disagreed that experience was used to appoint managers irrespective of their gender. The data also showed that non-management respondents disagreed that experience was used to appoint managers irrespective of their gender.

The study showed that inexperienced managers lacked confidence. Such managers would not be able to operationalize the strategic objectives and goals of the SOE (Amundsen \& Martinsen, 2014). Hence the SOE does not contribute as much to the GDP as its counterparts in China (Scharmer \& Kaufer, 2013). Firstly, even though the study used an appropriate sample size and probability sampling technique, it was conducted at a business unit and not the entire parastatal or at other parastatals. In future, it is recommended that this study is conducted at other parastatals as they are the strategic assets that are used in China to contribute to GDP. Secondly, using cross-sectional research will paint a clearer picture of predictors or factors that adversely affect JS. It is recommended that a follow-up study be conducted and extended to other business units at the parastatal. In future, researchers can investigate how age mediates the relationship between the predictors and JS, as it is predicted that more employees entering the job market in years to come will be Millennials (Linden, 2015:92). The following recommendations are made for the managers at the parastatal: 
- Hire employees based on experience during the recruitment and selection process;

- Make the recruitment and selection process transparent so that non-management negative perceptions are addressed;

- Management appointments should not be discriminatory based on gender, but it must be based on merit, qualifications, and experience;

- Train supervisors on how to communicate and implement the parastatal's strategy; and

- Train supervisors on interpersonal skills, so that they can motivate employees to implement the parastatal's strategy.

The results or data of the study can be utilized by managers and recruiters in the parastatal to use correct selection criteria when acquiring talent. It is also essential for training managers to develop interventions (i.e. strategy implementation, coaching, and mentoring) to capacitate supervisors who were appointed without the necessary experience. In terms of policymakers, the results show that they must review the recruitment and selection policy to also include experience. Previous research at the parastatal revealed that even though they must implement transformation policies or agendas, they must also factor in experience or the potential to be developed (Maleka \& Rankhumise, 2014). This study measured predictors that adversely affected JS. Using robust statistics like logit and Bayesian analyses, the researchers were able to select three predictors out of 25. Theoretically, the predictors are related to talent management (i.e. recruitment and selection, appointment, and confidence in goal achievement). In the literature, it was argued that acquiring talent is expensive and must be done correctly, and supervisors who are confident and competent will have positive views and encourage and motivate staff to achieve strategic goals. By achieving organizational goals, and performing optimally like their counterparts in China, employees with sufficient skills will be appointed.

\section{References}

Adisa, T. A., Osabutey, E. L. C., Gbadamosi, G. \& Mordi, C. (2017). The challenges of employee resourcing: the perceptions of managers in Nigeria. Career Development International, 22(6), 703-723.

Amakiri, D. \& Luke, G. R. (2015). Job design and employee absenteeism: a case study of some government parastatals in Nigeria. International Journal of Secondary Education, 3(6), 67-71.

Amundsen, S. \& Martinsen, O. L. (2014). Self-other -agreement on empowering leadership: relationship with leader effectiveness and subordinates' job satisfaction and turnover intentions. The Leadership Quarterly, 25, 784-800.

Ben-Hur, S. \& Kinley, N. (2016). The missing piece in managing employee behavior. Perspective for Managers, 192, 1-4.

Bless, C., Higson-Smith, C. \& Sithole, L. (2013). Fundamentals of Social Research Methods, 5th ed., Juta: Cape Town.

Browne, W. \& Goldstein, H. (2010). MCMC sampling for a multilevel model with no independent residuals within and between cluster units. Journal of Educational and Behavioral Statistics, 35(4), 453-473.

Buitenbach, J. H. \& De Witte, H. (2005). Job insecurity, extrinsic and intrinsic job satisfaction an effective organizational commitment of maintenance workers in a parastatal. South African Journal of Business Management, 36(2), 27-37.

Bussing. A., Falkenberg, Z., Schoppe, C., Recchia, D. R. \& Poier, D. (2017). Work stress associated cooldown reactions among nurses and hospital physicians and their relation to burnout symptoms.BMC Health Services Research, 17(551),1-3.

Bute, M. (2011). The effects of nepotism on employee behaviors and human resources practices. Review of Public Administration,5(1), 185-208.

Carolissen, L. K. \& Smith, D. C. (2014). Motivating IT staff in government organization in South Africa, in Proceedings of the e-Skills for knowledge production and innovation conference 2014, Cape Town, South Africa, pp. 61-71, available at: http://proceedings.e-skills-conference.org/2014/e-skills061071Carilissen721.pdf (accessed 15 January 2018).

Dacri, R. (2015). A manager's performance appraisal: prepare with confidence. Public Management, 9(6), 610.

Fahr, J., Earley, P. C. \& Lin, L. (1997). Impetus for action: a cultural analysis of justice and organizational citizenship behavior in a Chinese society, Administrative Science Quarterly, 42(3), 421-444. 
Gopane, D. \& Magang, T. I. T. (2016). Extent and effects of employee turnover on parastatal organizations in Botswana. Journal of Management Research and Analysis, 3(1), 12-27.

Graham, A. (2013). Statistics: A Complete Introduction, Hodder and Stoughton Ltd, London.

Haile, G. A. (2015). Workplace job satisfaction in Britain: evidence from linked employer-employee data. Labour, 29(3), 225-242.

Hair, J. F., Black, W. C., Babin, B. J. \& Anderson, R. E. (2010). Multivariate Data Analysis: A Global Perspective, 7th ed., Pearson Education, Upper Saddle River.

Hosmer, D. W., Lemeshow, S. \& Sturdivant, R. X. (2013). Applied Logistic Regression, Wiley and Sons Inc. New York.

Jha, S. \& Bhattachryya, S. S. (2012). Study of perceived recruitment practices and their relationship to job satisfaction. Synergy, 1, 63-76.

Jooste, G. (2014). The Impact of Employee Equity or the Job Satisfaction of Employees at De Beers Sightholder Sales South Africa, Unpublished Master's Dissertation, University of the Free State, Bloemfontein, South Africa.

Khoza, M. \& Kanjere, M. (2014). Job satisfaction, security and staff retention in public companies. A Case of Eskom. Journal of Public Administration, 49(1), 64-74.

Kianto, A., Vanhala, M. \& Heilmann, P. (2016). The impact of knowledge management on job satisfaction. Journal of Knowledge Management, 20(4), 621-636.

Kithinji, E. (2016), Challenges women leaders face in Kenyan parastatals. International Journal of Current Business and Social Sciences, 1(5), 15-32.

Korschun, D., Bhattacharya, C. B. \& Swain, S. D. (2014). Corporate social responsibility, customer orientation, and the job performance of frontline employees. Journal of Marketing, 8(3), 20-37.

Legoabe, R. S. (2017). Barriers that affect the practice of civil engineering in the South African local government sector, Unpublished Doctoral Dissertation, Tshwane University of Technology.

Labuschagne, M., Bosman, J. \& Buitendach, J. H. (2005). Job insecurity, job satisfaction and work locus of control of employees in a government organization. South African Journal of Human Resource Management, 3(2), 26-35.

Lahner, J. M., Hayship, B., McKelvy, T. N. \& Caballero, D. M. (2014). Employee age and reactions to downsizing. International Journal of Aging and Human Development, 79(3), 225-255.

Linden, S. (2015). Job expectations of employees in the Millennial generation. Unpublished Doctoral Dissertation, Walden University, Minneapolis, USA.

Maleka, M. J. (2012). An in-depth investigation of the factors contributing to employee dissatisfaction at the Business Application Solution Centre (BASC), Eskom, Unpublished Doctoral Dissertation, University of South Africa (UNISA), Pretoria, South Africa.

Maleka, M. J. \& Ranhumise, E. M. (2014). The impact of management practices on job satisfaction: insights from a state-owned institution. Problems and Perspectives in Management, 12(4), 476-484.

Maunganidze, F., Mashavira, N. \& Mapira, N. (2017). When the employer neglects his contractual obligation push and pull factors for employees to come to work which is not paid: a case of Zimbabwean parastatals. Journal of Business and Financial Affairs,6(2), 1-6.

Mensah, J. K. \& Bawole, J. N. (2017). Person-job-fit matters in parastatal institutions: testing the mediating effect of person-job-fit in the relationship between talent management and employee outcomes. International Review of Administrative Sciences, 85(4),2-17.

Munyengabe, S., Haiyan, H., Yiyi, Z. \& Jiefei, S. (2017). Factors and levels associated with lecturers' motivation and job satisfaction in a Chinese university. Eurasia Journal of Mathematics, Science and Technology Education,13(10),6415-6430.

Mutanda, D. (2014). The impact of the Zimbabwe Crisis On Parastatals. International Journal of Politics and Good Governance, 5(5), 1-14.

Nel, P. S., Kirsten, M., Swanepoel, B. J., Erasmus, B. J. \& Jordaan, B. (2016). South African Employment Relations: Theory and Practice, 8th ed. Van Schaik Publishers, Pretoria.

Ongunlana, E. K., Oshinaike, A. B. \& Ibrahim, R. O. (2016). Causal relationship between organizational commitment and job satisfaction of library and informational professionals: a canonical correlation analysis. Library Philosophy and Practice,1414, 1-20.

Otieno, J. F. (2016). Factors influencing satisfaction of management employees in state corporations: a case of postal corporation of Kenya. Unpublished Master's Dissertation, Strathmore University, Kenya. 


\section{Journal of Economics and Behavioral Studies (ISSN: 2220-6140)}

Vol. 10, No. 2, pp. 199-208, April 2018

PwC. (2015). Technical report: State-owned enterprises: catalysts for public value? available at: https://www.pwc.com/gr/en/publications/government/state-owned-enterprises-catalysts-forpublic-value-creation.html (accessed 17 January 2018).

Revuelta, J. \& Ximenez, C. (2017). Bayesian dimensionality assessment for the multidimensional nominal response model. Frontiers in Psychology, 8(9), 1-16.

Rossler, W. (2012). Stress, burnout, and job dissatisfaction in mental health worker. European Archives of Psychiatry and Clinical Neuroscience,262(2), 65-69.

Saari, L. M. \& Judge, T. A. (2004). Employee attitudes and job satisfaction. Human Management, 43(4), 395407.

Scharmer, O. \& Kaufer, K. (2013). Leading from the emerging future: from an ego-system to eco-system, Berret-Koehler Publishers, Oakland.

Sheldrick, R. C., Chung, P. J. \& Jacobson, R. M. (2017). Math matters: how misinterpretation of odds ratios and risk ratios may influence conclusions. Academic Pediatrics, 17, 1-3.

South Africa. The Public Service Commission. (2005). A toolkit on recruitment and selection, available at: http://www.psc.gov.za/documents/docs/guidelines/PSC\%20Toolkit.pdf (accessed 17 January 2018).

Spector, P. E. (1985). Measurement of human service staff satisfaction: development of job satisfaction survey. American Journal of Community Psychology, 13, 693-713.

Spector, P. E. (2012), Industrial and Organizational Psychology: Research and Practice. John Wiley \& Sons Inc: USA.

Steyn, R. (2014). Perceptions about gender-based discrimination in a selection of South African companies. Unpublished Master's Thesis, North-West University, Potchefstroom, South Africa.

Tufail, M. S., Muneer, S. \& Ishtiaq, M. (2016). Job Characteristics with Task and Contextual Performance: Moderating Role of Procedural Justice for Front Line Managers. Journal of Social Sciences, Special Issue, 299-508.

Van Eeden, D. (2014). The role of the chief human resource officer, Knowers Resources, Randburg.

Witt, M. A. (2017). Physician recruitment and retention in Manitoba: results from a survey of physicians' preferences for rural jobs. Canadian Journal of Rural Medicine, 22(2), 43-53. 